\title{
Biblioterapia e Hermenêutica: revisitando Gadamer e Ouaknin
}

\section{Carla Sousa}

\author{
Mestre em Ciência da Informação pelo Programa \\ de Pós-graduação em Ciência da Informação da \\ Universidade Federal de Santa Catarina \\ (PGCIN/UFSC)
}

Clarice Fortkamp Caldin

\begin{abstract}
Professora do Programa de Pós-graduação em Ciência da Informação da Universidade Federal de Santa Catarina (PGCIN/UFSC)
\end{abstract}

http://dx.doi.org/10.1590/1981-5344/3197

Apresenta alguns conceitos do campo da filosofia hermenêutica e faz uma relação com elementos do processo biblioterapêutico visando o cuidado com o ser. Explora o pensamento dos filósofos Ouaknin e Gadamer e de autores de diferentes áreas como a Ciência da Informação, Literatura, Antropologia e Psicologia. A pesquisa é exploratória, de caráter bibliográfico e abordagem qualitativa. Conclui que a Biblioterapia vai além do cuidado por meio das histórias e enfatiza a importância do diálogo, da interação e da interpretação no processo biblioterapêutico.

Palavras-chave: Biblioterapia. Hermenêutica. Interpretação. Diálogo. Interação.

\section{Bibliotherapy and Hermeneutic: revisiting Gadamer and Ouaknin}

It presents some concepts present in the field of hermeneutical philosophy and makes a relation with elements of the bibliotherapeutic process in the care of being. It explores the thinking of the philosophers Ouaknin and Gadamer, at the same time that it dialogues with authors of different areas like Information Science, Literature, Anthropology and Psychology. It is based on an exploratory bibliographic research with a bibliographic view and a qualitative approach. It concludes that Bibliotherapy goes beyond care through the stories and 
emphasizes the importance of dialogue, interaction and interpretation in the bibliotherapeutic process.

Keywords: Bibliotherapy. Hermeneutic. Interpretation.Dialogue. Interaction.

Recebido em 21.06.2017 Aceito em 09.05.2018

\section{Introdução}

O termo Biblioterapia diz muito pouco sobre o que de fato é. De acordo com a etimologia, o seu significado está associado à junção de duas palavras de origem grega, que vem a ser: livro e terapia. Logo, convenciona-se dizer que a Biblioterapia é um tipo de terapia que ocorre por meio dos livros.

Mas, entendemos que a concepção de Biblioterapia vai além disso e pode ser traduzida como o cuidado com outro por meio das histórias, sejam eles lidas, narradas ou dramatizadas. Esse cuidado também se dá por meio do diálogo e da interação com todos os envolvidos no processo para que seja possível a produção de sentido e construção de um novo texto e de um novo eu, o que ocorre a partir da interpretação e da compreensão.

Diante disso, e por ser a Biblioterapia um campo interdisciplinar, buscamos suporte na Filosofia, para compreender melhor alguns conceitos presentes no processo biblioterapêutico. Em especial, na filosofia hermenêutica, traduzida como a arte da interpretação e que tem como um dos principais expoentes o filósofo alemão Hans-Georg Gadamer.

O entrelaçamento da Biblioterapia com a Hermenêutica está muito presente no trabalho de outro filósofo, o francês Marc-Alain Ouaknin, que chegou a criar o termo Biblioterapia Hermenêutica, pois segundo ele a interpretação se configura como uma terapia. Portanto, esse autor é uma das referências sobre o assunto, apesar desse aspecto de sua obra ainda ser pouco explorado na literatura.

Este artigo foi construído com base numa pesquisa bibliográfica. Além de autores da Filosofia, apresentamos também alguns provenientes de outras áreas como a Ciência da Informação, Literatura, Antropologia e Psicologia, a fim de criar um diálogo que faça sentido e possa contribuir com o entendimento teórico do campo da Biblioterapia, que é interdisciplinar em sua essência.

\section{Biblioterapia}

Em Biblioterapia não é o livro em si, entendido enquanto objeto, que terá uma função terapêutica. A terapia, ou seja, o cuidado com o outro, não se opera administrando 'o livro' como remédio, como medicamento. 'O livro' é apenas a cápsula que envolve a essência, a substância, o 
princípio ativo que poderá reestabelecer o equilíbrio e devolver a harmonia ao Ser.

Antes mesmo de existirem os livros já existia a Biblioterapia. Pois, desde que existiu a linguagem oral o ser humano vem transmitindo pensamentos e repassando o conhecimento a partir das histórias, que há muito são utilizadas de forma terapêutica, ou seja, com o objetivo de cuidar do outro. Como destaca Ouaknin (1996, p. 27): "A biblioterapia, uma novidade? Nem um pouco! Quanto mais longe remontarmos na História, mais encontraremos esta intuição terapêutica do livro e da narrativa".

Das palavras de Ouaknin (1996) destacamos a referência feita à narrativa, pois pouca atenção tem sido dada a essa prática que remete aos primórdios da Biblioterapia, ou seja, a oralidade, a contação de histórias.

Bortolin (2010, p. 37) afirma que existem especificidades entre o texto escrito e o oral, pois enquanto a escrita "congela um texto" a oralidade "dispersa"; além disso, "a oralidade não exige comprovação da autoria, a escrita sim".

Para falar de oralidade é preciso voltar no tempo, pois, pela fala, os seres humanos sempre sentiram a necessidade de repassar para os seus semelhantes o conhecimento sobre a natureza e a vida. Daí surgem as histórias, em especial os mitos que nas civilizações antigas, como a grega e a romana, desempenharam um papel relevante influenciando os seres humanos ao longo dos séculos. Segundo Brandão (1986, p.13), o mito "se apresenta como um sistema, que tenta, de maneira mais ou menos coerente, explicar o mundo e o homem".

De acordo com Estés (2014, p. 33, grifos da autora) a tradição oral de compartilhar histórias vem de "uma comunidade imensa e antiqüíssima [sic] composta de santos, trovadores, bardos, griots, cantadoras, chantres, menestréis, vagabundos, megeras e loucos", e ainda, "contar ou ouvir histórias deriva sua energia de uma altíssima coluna de seres humanos interligados através do tempo e do espaço, sofisticadamente trajados com farrapos, mantos ou com a nudez da sua época", e completa: "se existe uma única fonte das histórias e um espírito das histórias, ela está nessa longa corrente de seres humanos".

Assim como Ouaknin (1996), que fala da intuição terapêutica das narrativas de histórias como não sendo nenhuma novidade, Estés (2014, p. 516) também afirma que: "no seu sentido mais antigo as histórias são uma arte medicinal". No caso da autora, ela própria contadora de histórias, a tradição Ihe foi passada oralmente por meio das mulheres de sua família e ao longo de suas viagens. As contadoras mais antigas, conta Estés (2014, p. 33), com a sabedoria que o tempo e a experiência Ihes conferiram, afirmavam: "uma história é um medicamento que fortifica e recupera o indivíduo e a comunidade".

Diante disso, é possível prosseguir falando sobre a terapia por meio das histórias sem reduzir o conceito de Biblioterapia ao que a palavra sugere. E, portanto, escolhemos utilizar o conceito de Caldin (2010) que 
define Biblioterapia como a terapia por meio das histórias, sejam elas, lidas, narradas ou dramatizadas.

Em Biblioterapia, é comum utilizarmos a literatura como protagonista do processo, partindo do entendimento proposto por Candido (2011, p. 176) que define literatura como sendo "a manifestação universal de todos os homens em todos os tempos"; para ele "não há povo e não há homem que possa viver sem ela, isto é, sem a possibilidade de entrar em contacto com alguma espécie de fabulação", pois: "assim como todos os homens sonham todas as noites, ninguém é capaz de passar as vinte e quatro horas do dia sem alguns momentos de entrega ao universo fabulado".

Dito isso, o autor defende o direito à literatura para todas as pessoas. Pois se ninguém pode passar um dia inteiro "sem mergulhar no universo da ficção e da poesia, a literatura concebida no sentido amplo a que me referi parece corresponder a uma necessidade universal que precisa ser satisfeita" (CANDIDO, 2011, p. 177).

E é exatamente a efabulação, a imaginação, a fantasia, proporcionadas pelo texto literário, seja através da leitura, narração ou dramatização, que the confere um caráter terapêutico. Esse tipo de terapia proporciona equilíbrio ao ser humano, pois como entende Caldin (2010, p. 31), terapia não é "uma cura, no sentido restritivo da palavra, mas no sentido alargado de busca do equilíbrio e da harmonia do ser total".

Sendo assim, a Biblioterapia é uma prática capaz de beneficiar todas as pessoas, de qualquer faixa etária estejam elas em plena saúde ou enfermas, pois como afirma Caldin (2010, p. 62): "ela é válida tanto para o doente efetivamente diagnosticado como doente (internado ou não em um hospital), como para o ser que não percebe, de fato, como seu equilíbrio está comprometido, mas sente que lhe falta algo". A terapia nesse caso, ou seja, o cuidado, ocorre por meio das histórias, da literatura, conferindo equilíbrio para o ser humano e, portanto, um estado de saúde, mesmo que temporário.

\section{Hermenêutica}

Hermenêutica é uma palavra greco-erudita empregada para expressar a arte da compreensão ou interpretação (GADAMER, 2011). A origem do termo está vinculada ao nome do deus grego Hermes. Segundo Palmer (2006, p. 23) os gregos "atribuíam a Hermes a descoberta da linguagem e da escrita - as ferramentas que a compreensão humana utiliza para chegar ao significado das coisas e para transmiti-lo aos outros".

Filho de Zeus e Maia, Hermes ficou conhecido como o mensageiro dos deuses por conta da sua habilidade em transmitir as vontades dos deuses do Olimpo. Ele era o interlocutor, o tradutor, o interprete (BRANDÃO, 1986).

Daí o fato de que palavras como hermenêutica e hermenêutico derivarem da raiz do nome do mensageiro dos deuses, pois sugerem "o 
processo de trazer uma situação ou uma coisa, da inteligibilidade à compreensão", ou seja: "de tornar compreensível, especialmente enquanto tal processo envolve a linguagem" (PALMER, 2006, p. 23; 24, grifos do autor).

A hermenêutica, enquanto ramo da filosofia, possui diversos representantes. Para Mora (2005), inclusive, é difícil identificar quem são os filósofos hermenêuticos. No entanto, não há dúvidas em relação ao nome de Hans-Georg Gadamer como principal representante dessa linha de pensamento.

\subsection{Hermenêutica de Gadamer}

Gadamer nasceu em 1900, em Marburgo, na Alemanha. Ainda pequeno, sua família foi morar na região da Breslávia, atual Wroclaw na Polônia, onde seu pai exerceu o cargo de reitor da universidade. Ele viveu algum tempo nessa região até retornar para sua cidade natal na adolescência e ingressar na vida acadêmica. O filósofo teve uma vida longa e bastante produtiva. Poucas semanas antes de falecer, em 13 de março de 2002, aos 102 anos de idade, foi publicada sua última obra (GUERVÓS, 2011).

Para alguns admiradores de Gadamer, a essa idade parecia mesmo que ele havia "alcançado o olimpo da imortalidade [...] Não acredito que nenhum pensador haja desfrutado da perspectiva que Gadamer desfrutou, ou seja, de poder contemplar nossa realidade histórica de tão alto e durante tanto tempo" (GUERVÓs, 2011, p. 6, tradução nossa).

Sua grande obra Verdade e Método foi publicada em 1960, depois de muitos anos de trabalho intenso para colocar no papel e consolidar os fundamentos da sua hermenêutica filosófica. Para muitos, Verdade e Método é classificada como a obra mais importante da filosofia ocidental do século XX, depois de $O$ Ser e o Tempo de Heidegger, de quem Gadamer foi discípulo (GUERVÓS, 2011).

Segundo o filósofo alemão, o propósito da sua hermenêutica filosófica é o de "procurar por toda parte a experiência da verdade, que ultrapassa o campo de controle da metodologia científica, e indagar de sua própria legitimação, onde quer que a encontre" (GADAMER, 1997, p. 32).

Para ele a experiência da filosofia bem como a experiência da arte são modos de manifestação de uma verdade que não pode ser verificada com os meios da ciência positivista. A partir desse pensamento ele criou a expressão ciências do espírito onde inclui as ciências humanas e sociais, pois elas apresentam uma forma diferente de investigação, que "aproxima-se especialmente do âmbito das artes" (GADAMER, 1997, p. $15)$.

De acordo com Guervós (2011, p. 6, tradução nossa) para Gadamer a arte seria um modelo paradigmático para compreender o sentido da experiência hermenêutica: "E este tem sido, provavelmente, um dos desafios mais atraentes de sua obra, reivindicar outros métodos de verdade e certeza". 
Nesse ponto, abrimos um parêntese para observar que da mesma forma atua a Biblioterapia, já que se encontra dentro dos limites do que Gadamer define como 'ciências do espírito'. Para alguns autores, por exemplo, Caldin (2010) é muito clara essa relação do fazer bibliterapêutico com as artes.

A autora defende que a Biblioterapia de Desenvolvimento (não a clínica, executada por psicólogos) é um campo onde prevalece, sobretudo, a visão humana sobre o ser em contrapartida a uma visão especializada. Além disso, não obedece a regras e técnicas pré-definidas e, inclusive, permite o improviso. Sob esse ponto de vista é possível admitir que a Biblioterapia está intimamente ligada com a intuição e com aspectos sutis e subjetivos do ser humano (CALDIN, 2010), elementos que também estão presentes no campo da Hermenêutica.

No entanto, devemos pontuar que essa visão é questionada por alguns autores, a exemplo de Pinto (2005, p. 40) que advoga que "somente a leitura, sem um acompanhamento terapêutico, não se traduz em biblioterapia", mesmo aquela praticada por bibliotecários. Ponto de vista que é rebatido por Hasse (2004, p. 42), ao afirmar que "como arte, a Biblioterapia é não diretiva, ou seja, é escolha do leitor retirar do texto o que ele achar relevante para suas emoções, assuntos pessoais, objetivos, sem a intervenção de um facilitador".

Diferente de Pinto (2005), Hasse (2004, p. 42) entende que quando a Biblioterapia está no campo médico aí sim é essencial direcioná-la por meio de um facilitador "que usa uma abordagem psicológica". Nao sendo - caso daquela praticada por bibliotecários, ou seja, a Biblioterapia de Desenvolvimento, que não está no campo da ciência positivista, e sim das chamadas ciências do espírito definida por Gadamer.

Mas, retomando a questão da verdade apresentada por Gadamer, vale explicar que o entendimento da verdade é discutível nos meios acadêmicos. Chauí (2010) apresenta três concepções distintas de verdade que tem origem no termo grego alétheia, no latim veritas e no hebraico emunah.

No primeiro caso, aletheia, Chaui (2010, p. 99) afirma que "a verdade é uma qualidade das próprias coisas"; ela está manifestada aos nossos olhos e é oposta ao que está escondido; em latim, veritas, a verdade não se refere às coisas, mas sim "ao relato e ao enunciado, à linguagem, seu oposto, portanto, é a mentira ou falsificação"; já em hebraico, verdade é igual à confiança, especificamente em Deus e nas pessoas - "Emunah é uma palavra da mesma origem que amém, que significa: assim seja".

Para Chauí (2010, p. 99) a concepção de verdade é uma síntese dessas três palavras e, por isso: "se refere às coisas presentes (como na aletheia), aos fatos passados e à linguagem (como na veritas), e às coisas futuras (como na emunah)." Esse é um conceito que permeia o pensamento filosófico e está na base da compreensão das ciências.

Além de variar de acordo com a origem linguística do termo, a ideia de verdade varia de acordo com diferentes escolas filosóficas. E a 
concepção de Gadamer difere das correntes que associam a verdade à racionalidade, fundada pelos iluministas.

Gadamer, ao elaborar uma concepção de verdade para as ciências, atrelada à ideia de finitude e de historicidade do ser humano, deu margem para que pensemos nesta não como algo fechado, mas sim como algo temporal que se faz, se constrói no devir. Tornou-se assim, um dos grandes contestadores da construção de metodologias nas Ciências Humanas que buscassem dar conta dessa tal verdade a partir de critérios oriundos da objetividade e racionalidade positivista (OLIVEIRA, 2007, p. 4).

Em meio a essa discussão sobre verdade, vale destacar que a Hermenêutica lida inclusive com a compreensão do incompreensível (GADAMER, 2011). Sendo assim, onde estaria a verdade sob o ponto de vista hemenêutico?

Compreender o incompreensível, e compreender especialmente aquilo que quer ser compreendido envolve o todo da nossa capacidade de reflexão que, nas religiões, na arte dos povos e nos refletores da nossa tradição histórica, sempre coloca à disposição novas respostas e, com cada resposta, provoca novas questões. Isso é hermeneutica enquanto filosofia.

Dentro do que Gadamer (2011, p. 169) classifica como incompreensível estão algumas das grandes questões da humanidade, que sempre ocuparam os filósofos; tais questões abrangem: "os segredos do começo e do fim, do ser e do nada, do nascimento e da morte e, sobretudo, do bem e do mal".

Nesse amplo espectro de questionamentos, cabe uma infinidade de temas. Mas para se chegar próximo a uma resposta possível, a filosofia hermenêutica propõe "a superação de todo pré-entendimento que contemos do mundo" (ALEXANDRE, 2014, p. 29).

E é aí que está fundamentado o pensamento de Gadamer. Ele nos estimula a ler para além do texto. Para além daquilo que nos é dado ver (aletheia). É uma visão de mundo pautada na linguagem e no diálogo.

Para o filósofo "a linguagem somente tem seu verdadeiro ser na conversação, no exercício do mútuo entendimento" (GADAMER, 1997, p. 450). Isso porque ninguém está só no mundo. $E$ a linguagem é o que aproxima o indivíduo da verdade, seja através da fala ou dos textos, para melhor entender a si mesmo, os outros e o mundo à sua volta.

O pensamento gademeriano sobre a linguagem e o diálogo contribui para o entendimento da Biblioterapia. Portanto, dedicamos alguns parágrafos à discussão desses conceitos e a relação existente com a prática da biblioterapia e o pensamento hermenêutico.

\section{Hermenêutica e Biblioterapia}

A linguagem é considerada para a hermenêutica de Gadamer "um acontecimento cujo sentido se trata de penetrar" (MORA, 2005, p. 1331). De fato, Gadamer (2011, p. 167) atribui tamanha importância à linguagem que chega a afirmar que um novo passo no pensamento 
filosófico é a "consciência de que não apenas a razão e o pensamento racional estão no centro da filosofia, mas também a linguagem, na qual tudo isso se expressa".

Segundo Palmer (2006, p. 51), Gadamer defende que "a hermenêutica é um encontro com o Ser através da linguagem", e é através desse fio condutor que o filósofo "mergulha nos problemas puramente filosóficos da relação da linguagem com o Ser, com a compreensão, a história, a existência e a realidade".

"A arte de podermos ouvir-nos uns aos outros e a força de poder escutar o outro, isso é o novo, e nisso consiste o universal de toda hermenêutica" (GADAMER, 2011, p. 168). Aqui o filósofo apresenta o diálogo como indispensável. Ousamos acrescentar que é nisso que reside a beleza do existir no mundo, pois não estamos sós. É através do outro que nos reconhecemos e temos parâmetros para seguir nosso desenvolvimento enquanto seres humanos.

Além da linguagem e do diálogo, a faculdade do pensamento também é destacada pelo filósofo. Antes mesmo da expressão exterior da fala que nos aproxima do outro, "o pensamento é o diálogo da nossa mente consigo mesma" (GADAMER, 2011, p. 168). O que em outras palavras pode ser caracterizado como introspecção, que ao lado da linguagem e do diálogo, são alguns dos elementos chave da Biblioterapia.

Subentendido nesses dois conceitos chaves do pensamento do filósofo - linguagem e diálogo - e também da Biblioterapia, está a ideia de interação, que ocorre tanto entre o texto e o indivíduo, quanto entre os próprios participantes da atividade biblioterapêutica.

Para Hasse (2004, p. 41), inclusive, o que diferencia uma simples leitura de uma leitura terapêutica é que, dentre outros fatores, "o ato da leitura para curar é um processo interativo". Com base nisso, acreditamos que o termo interagente se torna mais apropriado para denominar esse Ser que participa de forma ativa nesses processos.

$\mathrm{Na}$ Biblioterapia, o interagente é aquele que participa de atividades biblioterapêuticas dentro ou fora de uma biblioteca, seja em grupo ou individualmente, e que se coloca no processo de forma ativa, abrindo-se para o diálogo. É possível identificar alguns níveis de interação do indivíduo nos processos de leitura terapêutica. Ele interage tanto com o livro, ou o texto, quanto com aqueles que compartilham das atividades (SOUSA; CALDIN, 2016, p. 6).

Esse termo é utilizado em diversos contextos, inclusive no campo da Biblioteconomia. Para Corrêa (2014) a palavra interagente seria mais adequada do que a palavra usuário, comumente utilizada no contexto da biblioteca. Pois, segundo a autora, interagente é: "o sujeito social e cognitivo que busca informação com vistas a solucionar questões de ordem pessoal, profissional ou acadêmica"; nessa busca ele "conta com o bibliotecário na condução desse processo de forma mais interativa e parceira" (CORRÊA, 2014, p. 37).

Para conversar com essa proposta de utilização do termo interagente trazemos Bortolin (2010, p. 22) que opta pelos termos leitor- 
narrador e leitor-ouvinte no contexto da mediação oral da literatura onde ambos são compreendidos como sujeitos atuantes no processo: "Antes que os conceitos de leitor-narrador e leitor-ouvinte possam transparecer a concepção de indivíduos passivos, lembro que no momento da narrativa oral ambos interferem na ação do outro", ou seja, interagem entre si, o que ocorre "muitas vezes de forma inconsciente, por meio de gestos, olhares, sorrisos, cochichos, palavras etc".

Como afirma Petit (2013, p. 43-44), "os leitores não são páginas em branco onde o texto é impresso. Os leitores são ativos, desenvolvem toda uma atividade psíquica, se apropriam do que leem, interpretam o texto...". Logo, interagem. Eles dão a sua contribuição na construção do texto e de si mesmos, uma atitude alicerçada no pensamento hermenêutico.

Em relação a esse nível de interação, apresentamos o ponto de vista de Iser (1999), para quem o processo de leitura é uma interação dinâmica entre texto e leitor. Defende que "autor e leitor participam de um jogo de fantasia" e, ainda, "a leitura só se torna um prazer no momento em que nossa produtividade entra em jogo, ou seja, quando os textos oferecem a possibilidade de exercer as nossas capacidades" (ISER, 1999, p. 10).

Nesse sentido, Petit (2013, p. 27) lembra que "o leitor não consome passivamente um texto, ele se apropria dele, o interpreta, deturpa seu sentido, desliza sua fantasia, seu desejo, suas angustias entre as linhas e as mescla com a do autor", e completa: "é aí, em toda essa atividade fantasmática, nesse trabalho psíquico, que o leitor se constrói".

No entanto, segundo Iser (1999, p. 9) essa construção de si só ocorre quando o texto consegue "ativar certas disposições da consciência - a capacidade de apreensão e de processamento", na medida em que se refere "a normas e valores, como por exemplo o comportamento social dos seus possíveis leitores", dessa forma "o texto estimula os atos que originam a sua compreensão", ou seja possibilita uma atitude hermenêutica de interpretar e compreender.

Cabe aqui a seguinte afirmação de Gadamer (1997, p.571): "a leitura compreensiva não é repetição de algo passado, mas participação num sentido presente". Assim, o que o interagente faz na medida em que participa ativamente do processo de leitura, enquanto leitor-ouvinte ou leitor-narrador, é uma construção de si, como afirmou Petit.

Nessa participação, explica Iser (1999, p. 13), "o leitor se move constantemente no texto", a fim de que ele se transfira para sua consciência e então possa fazer sentido, essa construção de sentido é o que vai caracterizar uma relação bem-sucedida entre o texto e o leitor. É exatamente isso que ocorre na concepção da Biblioterapia Hermenêutica de Ouaknin, que explicaremos mais adiante.

Outro nível de interação presente no contexto biblioterapêutico e que está fundamentado numa visão tanto hermenêutica quanto fenomenológica é a relação entre os indivíduos, a relação com o outro. $O$ interagente, nesse caso, utiliza a sua intercorporeidade a fim de se fazer presente no mundo e tocar o outro, através do corpo ou da fala. Como 
afirma Petit (2013, p. 67) "a leitura é uma abertura para o outro, pode ser o suporte para os intercâmbios".

No entanto, a fim de estreitar a discussão, nos detemos numa perspectiva de tais relações como prerrogativa para o bem-estar dos seres humanos, partindo do principio de que o "ser-são é o ser que convive com - outro, pois sozinho ele estaria doente, ou seja, algo lhe faltaria" (CALDIN, 2010, p. 29).

De fato, para Gadamer (2011) é através do diálogo, da fala, que a intercorporiedade ocorre. E o filósofo utiliza como exemplo a relação do médico e do paciente. Diante da distância comumente estabelecida entre esses dois sujeitos, o filósofo sugere que ambos encontrem "um solo comum no qual possam se entender", afinal, para ele, a saúde não é algo exterior ao Ser humano, "é próprio da natureza humana manter-se em harmonia com a natureza" (GADAMER, 2011, p. 132; 144).

Esse diálogo entre médico e paciente ao qual ele se refere, é aquele da vida comum, "que não é conduzido por ninguém, mas que conduz todos nós" e, nesse sentido, "o diálogo apenas faz com que o outro, sem que volte a se desorientar, vislumbre a possibilidade de despertar a sua própria atividade interna, a qual o médico chama de colaboração" (GADAMER, 2011, p. 142).

Nesse espaço do diálogo acontece a interação entre médico e paciente, ou como preferimos chamar, o interagente. Pois, no diálogo os sujeitos são ativos e é essa ação de ambos os personagens que resultará na cura, ou no reestabelecimento da saúde e do equilíbrio.

Essa discussão se torna muito pertinente na medida em que na Biblioterapia lidamos com pessoas que, em maior ou menor escala, em nível consciente ou inconsciente, buscam restaurar o equilíbrio perdido.

Nesse sentido, Ouaknin (1996, p. 14) defende que: "Curar alguém é fazer falar e observar todos os obstáculos a essa palavra no corpo. A palavra é o sopro da vida do homem $[\ldots] "$.

Dito isso, o próprio Ouaknin (1996, p. 15) indaga; "de que palavra se trata? A do terapeuta? A do paciente?" e em seguida afirma "se trata de uma interação dessas duas palavras em um diálogo", e conclui:

Efetivamente, é sempre a nossa palavra que é o movimento e o sopro de nossa vida. Mas acontece com frequência que a palavra do outro ativa o nosso universo psíquico e nos transmite emoções que sentimos em nós mesmos (OUAKNIN, 1996, p. 15, grifo do autor).

Vimos que a Biblioterapia configura-se a todo momento como um diálogo, seja entre o texto e o interagente, entre o indivídio e sua própria consciência, ou entre eu e o outro. Nesse diálogo, uma questão fundamental, que é foco da hermenêutica é a compreensão ou interpretação, que também ocorre em vários níveis.

Nesse sentido, Ouaknin (1996, p. 19) advoga que "toda leitura implica um fenômeno de interpretação, que o ato de interpretação é inerente à leitura e que a interpretação é, em si, uma terapia". É baseado nesse pensamento que ele defende a ideia da Biblioterapia Hermenêutica. 
Segundo o autor, a Biblioterapia Hermenêutica "é uma atividade de leitura e de comentário" e "se situa na corrente da hermenêutica existencial, que é uma defesa da subjetividade e do direito à fala falante de um 'Eu', e não à fala falada do 'nós' da instituição" (OUAKNIN, 1996, p. 20-22, grifo do autor).

Aqui o autor faz referência a Merleau-Ponty muito presente na obra de Caldin. Com base no pensamento do filósofo francês, a autora defende que a Biblioterapia, a partir do encantamento próprio do texto literário, permite a "passagem da fala falada à fala falante", ou seja, "permite ao leitor, ouvinte ou espectador ultrapassar as significações do mundo cultural e criar novas significações, uma nova maneira de compreender 0 mundo" (CALDIN, 2010, p. 84-85).

Ouaknin (1996, p. 227, grifo do autor) explica que a fala falante é a nossa fala enquanto a fala falada pertence a outros, ou seja, "quando a fala não nos pertence, somos falados, como se alguém falasse em nós". Nas palavras de Caldin (2011, p. 23) com base na teoria merleaupontyana: "A linguagem falada é o conjunto das significações de uma língua; a linguagem falante é transfiguração dessas significações. É da fala falante, produtora de significados, que se ocupa a biblioterapia".

Essa fala externa não desperta o ser, e sendo assim, não contribui para o seu desabrochar. Pois, "um corpo só desabrocha para a humanidade do humano a partir não somente da linguagem, mas ainda da sua linguagem" (OUAKNIN, 1996, p. 228, grifo do autor).

E aqui citamos Petit (2013, p. 47, grifo da autora), para quem: "a leitura às vezes faz surgir palavras no leitor, fecunda-o. Nesse diálogo, ele ou ela pode começar a dizer eu, a formular um pouco suas próprias palavras, seu próprio texto, entre as linhas lidas".

Essa palavra própria de cada ser construída a partir da obra literária é o toque de humanidade presente no humano. É nesse processo que se concretiza a visão de Candido (2011) que entende a literatura como instrumento de humanização do ser humano na medida em que auxilia no exercício da reflexão, na aquisição do saber, na empatia, no refinamento das emoções, e no cultivo de tantas outras capacidades inatas.

No entanto, esse processo de humanização do homem requer um despertar, requer uma atitude hermenêutica, como defende Ouaknin, pois está diretamente condicionada à fala falante, aquela que pertence ao próprio indivíduo. Daí a importância da leitura enquanto interpretação incorporada no conceito de Biblioterapia Hermenêutica, a qual:

[...] consiste essencialmente, por intermédio da leitura interpretativa, em continuar fazendo viver as palavras no homem, em fazer circular a energia simbólica, em fazer de tal modo que as palavras se façam história, dinamização do tempo pelo estouro dos nós do ser portados-inscritos nas palavras exteriores ao individuo que as profere. [...] A leitura biblioterapêutica faz sair da petrificação do ser, que se assenta na petrificação das palavras. A hermenêutica não é uma possibilidade do mundo, mas uma necessidade incontornável (OUAKNIN, 1996, p. 229). 
O movimento de criação, do desatar dos nós e de superação da petrificação do ser está intimamente ligado à interpretação. E é nesse interpretar das palavras que é possível construir um sentido para a existência. Nas palavras de Caldin (2010, p. 64) na Biblioterapia, "o cuidado se volta para o leitor ou ouvinte do texto literário, que, singulares em sua existência, podem abrir-se para o mundo". Abertura que só é possível depois de desatados os nós que roubam a liberdade do Ser.

Essa libertação através da literatura permite que o ser humano possa construir o sentido de si mesmo e do mundo, pois como afirma Ouaknin (1996, p. 25): "o homem não tem sentido, ele se dá um. O mundo tampouco tem sentido, o homem vai dar-lhe um". E é exatamente por meio da interpretação e da fala falante que se cria algo novo.

É nesse encontro do indivíduo com uma história lida, narrada ou dramatizada, que ocorre a criação e a libertação que conduzirá ao equilíbrio, a base da Biblioterapia, que nas palavras de Ouaknin (1996, p. 197-198, grifo do autor): "funda-se em uma prática de leitura que permite ao homem ir ao mais profundo de si mesmo e se inventar a cada vez de maneira diferente", e ainda: "pela leitura e pela interpretação o tornar-se texto é também um tornar-se homem".

Dito isso, lembramos de Paulo Freire para quem o conceito de leitura ultrapassa o simples ato de decodificar símbolos através da palavra escrita; para ele a leitura do mundo precede a da palavra e implica uma prática consciente de poder transformá-lo, "de escrevê-lo ou de reescrevê-lo" (FREIRE, 1989, p. 13). Essa transformação do mundo, no entanto, passa pela transformação e pelo reescrever do próprio ser humano.

Nesse sentido, citamos também Todorov (2009, p. 32), pois ele acredita que as pessoas leem literatura "não para melhor dominar um método de ensino, tampouco para retirar informações sobre as sociedades a partir das quais foram criadas", mas sim, para nela encontrar um sentido que Ihes "permita compreender melhor o homem e o mundo, para nelas descobrir uma beleza que enriqueça sua existência", pois, "ao fazêlo, ele compreende melhor a si mesmo. O conhecimento da literatura não é um fim em si, mas uma das vias régias que conduzem à realização pessoal de cada um".

Aí reside a força da palavra, do texto, seja lido, narrado ou dramatizado. Como afirma o filósofo hermenêutico Paul Ricoeur (1986, p. 31 apud Ouaknin, 1996, p. 199, grifo do autor): "compreender um texto é se compreender. Compreender-se é compreender-se diante do texto e receber dele as condições de um si, outro que o eu que lê". Diante de tal afirmação, Ouaknin completa que a Biblioterapia Hermenêutica está situada exatamente nessa relação dialética entre o ser humano e o texto.

Nesse sentido, o que deve ser compreendido, segundo Ouaknin (1996, p. 200), "não é a intenção do autor, mas o efeito do texto no leitor que recebe e se apropria do sentido". E aqui vale retomar Iser, para quem o texto possibilita um efeito prazeroso e libertador no leitor a partir do jogo que enseja no ato da leitura.

Segundo Caldin (2012, p. 6-7) com base no pensamento iseriano, 
Quando preenche os vazios do texto literário com suas lembranças e expectativas, o leitor viaja no imaginário, cria uma nova realidade em que possa transitar com prazer e segurança, esquecendo-se, nesses momentos, da realidade cotidiana. Nesse sentido, podemos afirmar que transforma 0 ato de ler em terapia.

Isso ocorre, pois o interagente nesse processo sabe que está participando de um jogo. "O jogo da ficção, cônscio de que transita em uma outra realidade onde tudo é possível e acaba bem" (CALDIN, 2012, p. 7).

Essa leitura, própria do processo biblioterapêutico, é definida por Ouaknin (1996, p. 97) como leitura-criadora, a qual, "abre para novos pensamentos e novos atos, inventa novos mundos, cuja novidade é também a renovação do sujeito leitor-criador"; ele chega a essa conclusão por acreditar antes de tudo que o ser humano é uma criação contínua: "em incessante movimento de tornar-se".

E nessa nova realidade construída a partir do texto, o leitor-criador lembra que "ele não contém apenas incontáveis possibilidades de poder ser, mas que ele tem precisamente o seu ser nesse poder ser múltiplo" (OUAKNIN, 1996, p. 202).

Essa lembrança, esse despertar, esse desabrochar só é possível graças ao ato de interpretar, de interagir com o texto, de jogar o jogo proposto pelo autor. Estando aberto para entrar no jogo, à maneira de Iser, ou na dança da Biblioterapia, ao nosso ver, o interagente se abre para essas infinitas possibilidades de poder ser.

Dito isso, finalizamos com Ouaknin (1996, p. 25, grifo do autor), para quem: "O homem está condenado a interpretar!", pois "a interpretação implica a própria possibilidade de existência, transcendência e liberdade", sendo assim, conclui o autor: "A vida é fundamentalmente ontologicamente - hermenêutica".

\section{Conclusão}

A Biblioterapia tem sua base teórica alicerçada em diversas áreas e é, portanto, interdisciplinar. Neste artigo exploramos a relação da Biblioterapia com a Filosofia, em especial com a filosofia hermenêutica que apresenta a questão da interpretação como chave para compreensão do mundo e do ser humano.

Vimos que a Hermenêutica tem como um dos principais representantes o filósofo alemão Gadamer. Nos seus trabalhos, ele enfatiza a importância da linguagem e da interpretação, além da interação e do diálogo como conceitos fundamentais para que possamos compreender o mundo, o outro e a nós mesmos. Tais conceitos também se fazem presente no fazer biblioterapêutico, o que levou outro filósofo, o francês Ouaknin, a pensar numa Biblioterapia Hermenêutica.

Ouaknin defende que toda leitura pressupõe uma interpretação, e que por meio desse ato o ser humano, que está em constante transformação, vai se delineando, tomando forma e criando um novo texto com suas próprias palavras. Como apresentado, entendemos o 
processo de leitura de uma forma mais ampla, esta não se limita ao texto escrito, nem ao objeto livro.

Em Biblioterapia, entende-se que o cuidado ocorre por meio do texto, das histórias, que podem ser lidas, narradas ou dramatizadas. Dito isso, e tomando como base o pensamento hermenêutico podemos concluir que o cuidado também ocorre por meio da interpretação, do diálogo e da interação, seja com o texto literário ou com os envolvidos no processo biblioterapêutico, o que contribui para uma melhor compreensão de mundo, de si mesmo e do outro e, consequentemente, para um viver mais harmônico, saudável e feliz.

\section{Referências}

ALEXANDRE, A. F. Metodologia científica e educação. 2. ed. rev. Florianópolis: Ed. da UFSC, 2014.

BORTOLIN, S. Mediação oral da literatura: a voz dos bibliotecários lendo ou narrando. 2010. 232f. Tese (Doutorado em Ciência da Informação) Universidade Estadual Paulista Júlio de Mesquita Filho, Marilia, 2010.

BRANDÃO, J. de S. Mitologia grega. Petrópolis: Vozes, 1986.

CALDIN, C. F. Biblioterapia: um cuidado com o ser. São Paulo: Porto de Idéias, 2010.

CALDIN, C. F. A leitura segundo Wolgang Iser. DataGramaZero, Rio de Janeiro, v. 13, n. 5, p. 1-7, out. 2012. Disponível em: <http://www.dgz.org.br/out12/Art_04.htm>. Acesso em: 28 dez. 2012.

CANDIDO, A. Vários escritos. Rio de Janeiro: Ouro Sobre Azul, 2011.

CHAUI, M. de S. Convite à filosofia. 14. ed. São Paulo: Ática, 2010.

CORRÊA, E. C. D. Usuário, não! Interagente: proposta de um novo termo para um novo tempo. Encontros Bibli: Revista Eletrônica de Biblioteconomia e Ciência da Informação, Florianópolis, v. 19, n. 41, p. 23-40, dez. 2014.2 Disponível em: <https://periodicos.ufsc.br/index.php/eb/article/view/15182924.2014v19n41p23/28292 >. Acesso em: 2 jun. 2015.

ESTÉS, C. P. Mulheres que correm com lobos: mitos e histórias do arquétipo da mulher selvagem. Rio de Janeiro: Rocco, 2014.

FREIRE, P. A importância do ato de ler: em três artigos que se completam. 23. ed. São Paulo: Cortez: Autores Associados, 1989.

GADAMER, H.-G. Verdade e método: traços fundamentais de uma hermenêutica filosófica. Petrópolis: Vozes, 1997.

GADAMER, H.-G. O caráter oculto da saúde. 2. ed. Rio de Janeiro: Vozes, 2011.

GUERVÓS, L. E. de S. Perfil de: Hans-Georg Gadamer (1900-2002). Málaga, 2011. Disponível em: 
<http://www.uma.es/gadamer/page6/index.htm>. Acesso em: 15 fev. 2016.

HASSE, M. Biblioterapia como texto: análise interpretativa do processo biblioterapêutico. 2004. 124f. Dissertação (Mestrado em Comunicação e Linguagens) - Universidade Tuiuti do Paraná, Curitiba, 2004.

ISER, W. O ato da leitura: uma teoria do efeito estético. São Paulo: Ed. 34, 1999. v. 2.

MORA, J. F. Dicionário de filosofia. 2. ed. São Paulo: Loyola, 2005.

OLIVEIRA, A. M. A constituição da verdade em Hans G. Gadamer e Michel Foucault. Revista aulas, Campinas, n. 3, p. 1-30, mar. 2007. Disponível em:

<https://www.ifch.unicamp.br/ojs/index.php/aulas/article/view/1912/137

2>. Acesso em: 10 set. 2016.

OUAKNIN, M.-A. Biblioterapia. São Paulo: Loyola, 1996.

PALMER, R. E. Hermenêutica. Lisboa: Ed. 70, 2006.

PETIT, M. Leituras: do espaço íntimo ao espaço público. São Paulo: Editora 34, 2013.

PINTO, V. B. A biblioterapia como campo de atuação para o bibliotecário. Transinformação, Campinas, v. 17, n. 1, p. 31-43, 2005. Disponível em: <http://www.scielo.br/pdf/tinf/v17n1/03.pdf>. Acesso em: 24 maio 2017.

SOUSA, C.; CALDIN, C. F. Biblioterapia aplicada com estudantes de Biblioteconomia da UFSC: uma vivência terapêutica com histórias. In: ENCONTRO NACIONAL DE PESQUISA EM CIÊNCIA DA INFORMAÇÃO, 17., 2016, Salvador. Anais... Salvador: ENANCIB, 106. p. 1-20. Disponível em: <www.ufpb.br/evento/Iti/ocs/index.php/enancib2016/enancib2016>. Acesso em: 4 mar. 2017.

TODOROV, T. A Literatura em perigo. Rio de Janeiro: DIFEL, 2009. 